\title{
Documentation of spontaneous functional closure of a ventricular septal defect during adult life
}

\author{
G. D. Schott \\ From the Department of Cardiology, Guy's Hospital, London
}

Spontaneous functional closure of a previously haemodynamically significant ventricular septal defect between the ages of 23 and 40 has been documented by serial cardiac catheterizations.

That spontaneous closure of a ventricular septal defect could occur was first suggested by French in 1918. Numerous subsequent authors have confirmed this suggestion both on clinical and on additional haemodynamic evidence, but nearly all reports have alluded to closure in infants and children. The following case report demonstrates almost complete closure of such a defect in a considerably older patient.

\section{Case report}

A congenital heart lesion was suspected in this man at the age of 4 , when a cardiac murmur was found during routine examination. On two occasions, at the ages of 12 and 16, he was confined to bed for some months on account of an undiagnosed febrile illness, considered to be bacterial endocarditis. Apart from these episodes, the second of which was treated with chloramphenicol, the patient has been asymptomatic.

At the age of 23, he was admitted for investigation, and examination was unremarkable apart from a systolic thrill and pansystolic murmur heard over the praecordium, maximal at the left sternal edge. Radiographic screening of the chest showed prominent pulmonary arteries with increased pulsation, and hyperactive left and right ventricles. The clinical and radiographic impression of a ventricular septal defect was confirmed at cardiac catheterization: a 15 per cent step-up in oxygen saturations at ventricular level, a pulmonary: systemic blood flow ratio of $2.5: \mathrm{I}$, and a left-to-right shunt of approximately $9 \mathrm{l} . / \mathrm{min}$ were demonstrated. Intracardiac pressures were normal (Table), and no abnormal communications could be crossed. Angiography was not performed.

He was seen again 17 years later, asymptomatic, at the age of 40. The signs on physical examination were unchanged, and the electrocardiogram and chest $x$-ray were normal. It was felt that the clinical findings were incompatible with the earlier investigations, and he was readmitted for a second catheterization. This showed no detectable step-up in oxygen saturations, and all intracardiac pressures (Table) were normal, apart from a right ventricular pressure of $38 / 0 \mathrm{mmHg}$ recorded on only a single occasion, and an infundibular pulmonary gradient of $6 \mathrm{mmHg}$. Left ventricular angiography revealed a small aneurysm of the left ventricular wall at the site of the membranous septum, and a very small jet of contrast medium leaving the left ventricle from the centre of the aneurysm was seen (Fig.). The cardiac output and pulmonary vascular resistance were normal.

TABLE Haemodynamic data

\begin{tabular}{|c|c|c|c|c|}
\hline Site & $\begin{array}{l}\text { I956 (age 23) } \\
\text { Blood pressure } \\
(\mathrm{mmHg})\end{array}$ & $\begin{array}{l}\text { Blood } \mathrm{O}_{2} \text { saturation } \\
(\%)\end{array}$ & $\begin{array}{l}\text { I973 (age } 40 \text { ) } \\
\text { Blood pressure } \\
(\mathrm{mmHg})\end{array}$ & $\begin{array}{l}\text { Blood } \mathrm{O}_{2} \text { saturation } \\
(\%)\end{array}$ \\
\hline $\begin{array}{l}\text { Superior vena cava } \\
\text { Right atrium } \\
\text { Right ventricle } \\
\text { Main pulmonary artery } \\
\text { Brachial artery } \\
\text { Aorta }\end{array}$ & $\begin{array}{l}- \\
5 / 3 \\
21 / 5 \\
19 / 11 \\
82 / 56 \\
-\end{array}$ & $\begin{array}{l}73 \\
78,73 \\
89,90 \\
91 \\
98^{\star} \\
-\end{array}$ & $\begin{array}{l}-6 / 3 \\
38 / 0,31 / 0 \\
25 / 5 \\
- \\
120 / 80\end{array}$ & $\begin{array}{l}78 \\
77,78,78 \\
81,82,79 \\
79,80 \\
96\end{array}$ \\
\hline
\end{tabular}

^ Assumed value. 


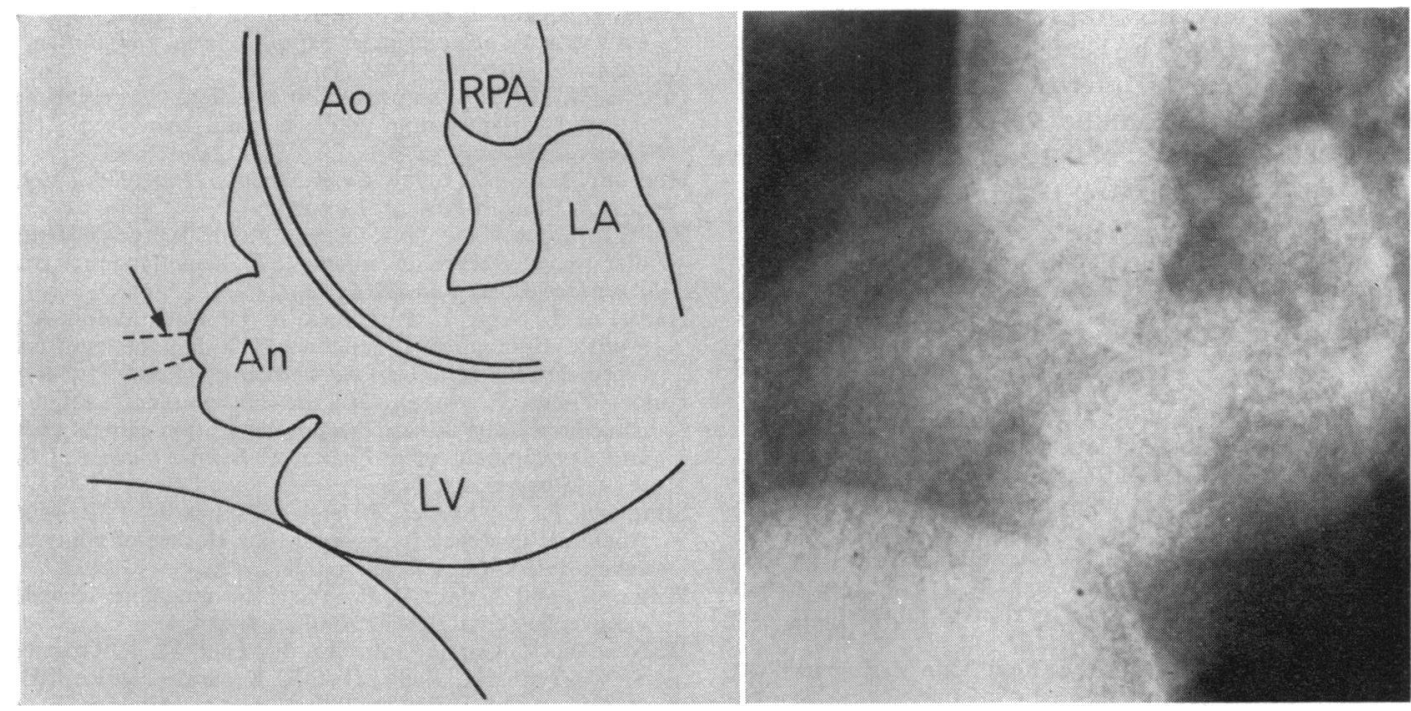

FIG. Left ventricular angiogram, in the left anterior oblique projection. Ao, aorta; LV, left ventricle; $L A$, left atrium; $R P A$, right pulmonary artery; $A n$, aneurysm; the jet from the left ventricle is indicated by the arrow.

\section{Discussion}

The present report documents the spontaneous and almost complete closure of a ventricular septal defect in a man between the ages of 23 and 40. Over the intervening 17 years, the considerable left-toright shunt has become haemodynamically insignificant, and indeed is only demonstrable by angiography. Over the same period, a minor infundibular pulmonary obstruction and slight right ventricular hypertension have developed.

The natural history of ventricular septal defects, including the aspect of their spontaneous closure, has been considered in the past (e.g. Bloomfield, 1964), and has recently been extensively reviewed (Campbell, 1971). Though spontaneous closure was suspected clinically as early as I918 (French, I918; Parkes-Weber, 1918), the first documentation by repeated cardiac catheterization was reported by Azevedo et al. (1958). Several other instances of cases in which spontaneous closure has occurred have since been published, and in many of these cases evidence of closure has been provided by serial cardiac catheterizations (Evans, Rowe, and Keith, 1960; Agustsson et al., I961 ; Nadas et al., 196I; Wade and Wright, 1963; Kidd et al., 1965; Walker et al., 1965).

Nearly all the reports cited above have alluded to infants or children. Closure in older age groups may also occur; rarely haemodynamic evidence has been provided in young adults, such as the patient described by Walker et al. (1965) in whom closure was shown to have occurred between the ages of 15 and 23. In necropsies of 1605 adults aged 39 to 90 , there was anatomical evidence suggesting the possibility of spontaneous closure in 7 , all of whom had been asymptomatic during life (Simmons, Moller, and Edwards, 1966). It has not been possible to find a report of documented spontaneous closure, albeit incomplete, of a ventricular septal defect during life in this older age group.

The anatomical basis for spontaneous closure, summarized by Hudson (1970), is often uncertain. The possibilities include adhesion of the septal cusp of the tricuspid valve, closure of the defect by a fibrous membrane, and diminution in the size of a muscular defect as the heart enlarges during infancy. In the present report, the angiographic appearances are consistent with a defect in the membranous septum: the aetiology of this closure is unknown, but it is possible that the aneurysm results from stretching of a fibrous scar which has virtually closed the defect.

The demonstration that a ventricular septal defect, even if initially associated with a large leftto-right shunt, may close spontaneously during adult life lends support to the opinion that management of patients with defects associated with normal 
pulmonary artery pressures may be conservative. Such patients should be kept under observation, and reinvestigated after an interval (Cleland et al., 1968). It is evident that the attainment of an adult age may be associated with spontaneous closure of such ventricular septal defects.

I am indebted to Dr. Edgar Sowton for help in preparation of this paper and permission to report this case.

\section{References}

Agustsson, M. H., Gasul, B. M., Arcilla, R. A., Bicoff, J. P., and Moncada, R. (I96r). Spontaneous closure of ventricular septal defect in eight children demonstrated by serial cardiac catheterizations and angiocardiography (abstract). Circulation, 24, 874.

Azevedo, A de C., Toledo, A. N., Carvalho, A. A. de, Zaniolo, W., Dohmann, H., and Roubach, R. (1958). Ventricular septal defect; an example of its relative diminution. Acta Cardiologica, 13, 513.

Bloomfield, D. K. (1964). The natural history of ventricular septal defect in patients surviving infancy. Circulation, 29, 914.

Campbell, M. (197I). Natural history of ventricular septal defect. British Heart fournal, 33, 246.

Cleland. W. P., Goodwin, J. F., Bentall, H. H., Oakley, C. M., Melrose, D. G., and Hollman, A. (1968). A decade of open heart surgery. Lancet, I, I9I.
Evans, J. R., Rowe, R. D., and Keith, J. D. (1960). Spontaneous closure of ventricular septal defects. Circulation, 22, 1044.

French, H. (19I8). The possibility of a loud congenital heart murmur disappearing when a child grows up. Guy's Hospital Gazette, 32, 87.

Hudson, R. E. B. (1970). Cardiovascular Pathology, Vol. 3. Sio42. Edward Arnold, London.

Kidd, L., Rose, V., Collins, G., and Keith, J. (1965). Ventricular septal defect in infancy. A hemodynamic study. American Heart fournal, 69, 4.

Nadas, A. S., Scott, L. P., Hauck, A. J., and Rudolph, A. M. (I96I). Spontaneous functional closing of ventricular septal defects. New England fournal of Medicine, 264, 309.

Parkes-Weber, F. (1918). Can the clinical manifestations of congenital heart disease disappear with the general growth and development of the patient? British fournal of Children's Diseases, $15,113$.

Simmons, R. L., Moller, J. H., and Edwards, J. E. (I966). Anatomic evidence for spontaneous closure of ventricular septal defect. Circulation, 34, 38.

Wade, G., and Wright, J. P. (I963). Spontaneous closure of ventricular septal defects. Lancet, $\mathbf{I}, 737$.

Walker, W. J., Garcia-Gonzalez, E., Hall, R. J., Czarnecki, S. W., Franklin, R. B., Das, S. K., and Cheitlin, M. D. (1965). Interventricular septal defect. Analysis of 4I5 catheterized cases, ninety with serial hemodynamic studies. Circulation, 3r, 54.

Requests for reprints to Dr. G. D. Schott, Department of Cardiology, Guy's Hospital, London SEr 9RT. 